\title{
Pneumoperitoneum-induced pneumothorax during laparoscopic living donor hepatectomy: a case report
}

\author{
Min Suk Chae ${ }^{1}$, Jueun Kwak², Kyungmoon Roh ${ }^{3}$, Minhee Kim', Sungeun Park, Ho Joong Choi ${ }^{5}$, Jaesik Park', \\ Jung-Woo Shim', Hyung Mook Lee ${ }^{1}$, Yong-Suk Kim¹, Young Eun Moon ${ }^{1}$ and Sang Hyun Hong ${ }^{1 *}$ (D)
}

\begin{abstract}
Background: We present a living donor case with an unexpected large-volume pneumothorax diagnosed using lung ultrasound during a laparoscopic hepatectomy for liver transplantation (LT).

Case presentation: A 38-year-old healthy female living donor underwent elective laparoscopic right hepatectomy. The preoperative chest radiography (CXR) and computed tomography images were normal. The surgery was uneventfully performed with tolerable $\mathrm{CO}_{2}$ insufflation and the head-up position. $\mathrm{SpO}_{2}$ decreased and airway peak pressure increased abruptly after beginning the surgery. There were no improvements in the $\mathrm{SpO}_{2}$ or airway pressure despite adjusting the endotracheal tube. Eventually, lung ultrasound was performed to rule out a pneumothorax, and we verified the stratosphere sign as a marker for the pneumothorax. The surgeon was asked to temporarily hold the surgery and cease with the pneumoperitoneum. Portable CXR verified a large right pneumothorax with a small degree of left lung collapse; thus, a chest tube was inserted on the right side. The hemodynamic parameters fully recovered and were stable, and the surgery continued laparoscopically. The surgeon explored the diaphragm and surrounding structures to detect any defects or injuries, but there were no abnormal findings. The postoperative course was uneventful, and a follow-up CXR revealed complete resolution of the two-sided pneumothorax.
\end{abstract}

Conclusion: This living donor case suggests that a pneumothorax can occur during laparoscopic hepatectomy due to the escape of intraperitoneal $\mathrm{CO}_{2}$ gas into the pleural cavity. Because missing the chance to identify a pneumothorax early significantly decreases the safety for living donors, point-of-care lung ultrasound may help attending physicians reach the final diagnosis of an intraoperative pneumothorax more rapidly and to plan the treatment more effectively.

Keywords: Pneumothorax, Laparoscopic surgery, Living donor, Liver transplantation, Lung ultrasound

\section{Background}

Laparoscopic donor surgery for liver transplantation (LT) reduces postoperative complications, such as surgical site infection and postoperative ascites, and also allows for a shorter hospital stay and earlier return to normal activities [1]. Therefore, it is ideal for living donors who have lived a

\footnotetext{
*Correspondence: shhong7272@gmail.com

'Department of Anesthesiology and Pain Medicine, Seoul St. Mary's Hospital, College of Medicine, The Catholic University of Korea, 222, Banpo-daero, Seocho-gu, Seoul 06591, Republic of Korea

Full list of author information is available at the end of the article
}

healthy life, and its adoption is rapidly increasing [2]. A laparoscopic donor hepatectomy is performed through $\mathrm{CO}_{2}$ insufflation of the abdominal cavity to achieve an optimal surgical view. However, laparoscopic surgery may cause severe $\mathrm{CO}_{2}$-related complications, such as pneumothorax, pneumoperitoneum, and subcutaneous emphysema [3]. Although the incidence of pneumothorax is low during laparoscopy-based surgery, the complication can be severe and life-threatening [4].

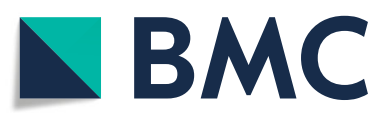

(c) The Author(s). 2020 Open Access This article is licensed under a Creative Commons Attribution 4.0 International License, which permits use, sharing, adaptation, distribution and reproduction in any medium or format, as long as you give appropriate credit to the original author(s) and the source, provide a link to the Creative Commons licence, and indicate if changes were made. The images or other third party material in this article are included in the article's Creative Commons licence, unless indicated otherwise in a credit line to the material. If material is not included in the article's Creative Commons licence and your intended use is not permitted by statutory regulation or exceeds the permitted use, you will need to obtain permission directly from the copyright holder. To view a copy of this licence, visit http://creativecommons.org/licenses/by/4.0/. The Creative Commons Public Domain Dedication waiver (http://creativecommons.org/publicdomain/zero/1.0/) applies to the data made available in this article, unless otherwise stated in a credit line to the data. 
Chest radiography (CXR) and computed tomography (CT) have largely been used as lung imaging tools to diagnose abnormal lung conditions in the emergency and critical care settings. However, the pitfalls of CXR are technical difficulties leading to limited accuracy and exposure of the patients to radiation $[5,6]$. There is an added need to mobilize patients for CT and expose them to higher radiation, in addition to poor repeatability and high cost $[7,8]$. A superior imaging option is lung ultrasound, which has many advantages, including easy bedside accessibility and reproducibility without invasive and radiative features [9].

Here, we present a living donor case with an unexpected large-volume $\mathrm{CO}_{2}$ pneumothorax diagnosed using point-of-care lung ultrasound during laparoscopic hepatectomy for liver LT.

\section{Case presentation}

A 38-year-old female living donor (height $162.3 \mathrm{~cm}$; weight $53.5 \mathrm{~kg}$; body mass index $20.3 \mathrm{~kg} / \mathrm{m}^{2}$ ) was scheduled for elective laparoscopic right hepatectomy for LT. She was clinically acceptable for donation surgery according to multidisciplinary assessments based on living liver donation guidelines $[10,11]$. She had no history of diabetes mellitus, hypertension, cerebro- and cardiovascular diseases, hepatitis or pneumothorax, and there were nonspecific physical findings. The CXR and chest CT image findings were nonspecific, and there was no evidence of fatty liver or focal hepatic lesions in abdominal CT images. Sinus rhythm was recorded on an electrocardiogram. A central venous catheter (Arrow 7 Fr catheter; Teleflex, Wayne, PA, USA) was implemented to administer intravenous fluids and medications without complications in the right internal jugular vein under sonographic guidance, and the patency of catheterization was confirmed by CXR. Her laboratory findings were as follows: hemoglobin, $12.0 \mathrm{~g} / \mathrm{dL}$; white blood cell count, $6.94 \times 10^{9} / \mathrm{L}$ (neutrophils, 57.2\%); platelet count, $271,000 / \mu \mathrm{L}$; creatinine, $0.64 \mathrm{mg} / \mathrm{dL}$; albumin, $4.2 \mathrm{~g} / \mathrm{dL}$; aspartate and alanine aminotransferase, $19 \mathrm{U} / \mathrm{L}$ and $11 \mathrm{U} / \mathrm{L}$, respectively; total bilirubin, $0.39 \mathrm{mg} / \mathrm{dL}$; and prothrombin time, $111.6 \%$ (INR: 0.94).

Balanced anesthesia was induced with $100 \mathrm{mg}$ propofol (Fresenius Kabi, Bad Homburg, Germany) and $50 \mathrm{mg}$ rocuronium (Merck Sharp \& Dohme Corp., Kenilworth, NJ, USA), and was maintained with desflurane (Baxter, Deerfield, IL, USA) in oxygen/medical air $\left(\mathrm{FiO}_{2} 50 \%\right)$ with volume-controlled mechanical ventilation (tidal volume: $400 \mathrm{~mL}$; respiration rate: $12 / \mathrm{min}$; inspiration and expiration ratio: 1:2). A neuromuscular block was maintained with rocuronium. Her vital signs (i.e., systolic [SBP] and diastolic [DBP] blood pressure; heart rate [HR]; and body temperature) and hypnotic depth (bispectral index monitor; Medtronic, Minneapolis, MN, USA) were continuously monitored and managed, as appropriate (Table 1$)$.
A laparoscopic hepatectomy was performed using the five-trocar technique and the trocars were placed uneventfully. Abdominal $\mathrm{CO}_{2}$ insufflation was performed with a pressure of $10-12 \mathrm{mmHg}$. The patient was placed in a $30^{\circ}$ head-up position to assist with surgical exposure. The harmonic scalpel (Ethicon Inc., Cincinnati, OH, USA), with transaction and hemostasis of the liver around tissues, was meticulously applied for liver mobilization.

Saturation of peripheral oxygen $\left(\mathrm{SpO}_{2}\right)$ decreased to $90 \%$, and airway peak pressure reached $35 \mathrm{cmH}_{2} \mathrm{O} 30$ min after beginning the laparoscopic surgery. Chest auscultation revealed normal breath sounds over the left chest but reduced breath sounds on the right. Because we assumed that this could be due to kinking or migration of the endotracheal tube or due to obstructive secretions in the endotracheal tube, we carefully checked the tube and smoothly toileted inside the tube using a fiberoptic bronchoscope. Chest auscultation and movement seemed to recover during inspiration and expiration. However, airway peak pressure abruptly reached $38 \mathrm{cmH}_{2} \mathrm{O}$ again and tidal volume simultaneously decreased to $180 \mathrm{~mL}$. Her hemodynamic parameters began to change as $\mathrm{SpO}_{2}$ was $88 \%$, end-tidal $\mathrm{CO}_{2}$ increased to $48 \mathrm{mmHg}, \mathrm{SBP} /$ DBP decreased to $82 / 41$, and HR reached 110 beats/ min. As a result, a sonographic examination of the lungs (Affiniti 70C ultrasound system; Philips, Amsterdam, the Netherlands) was performed to rule out pneumothorax, but we verified the lung points as a sonographic marker for occult pneumothorax in both anterior apical zones (Fig. 1). A pneumothorax was suspected, and the surgeon was asked to temporarily pause the surgery and cease gas insufflation. Lung ultrasound using a sterile drape was meticulously performed in the anterior apical zone (i.e., the mid-clavicular line at the second to third intercostal space) and lateral zone (i.e., the lateral-clavicular line at lateral and slightly superior to the nipple) with the patient in the supine position, and the stratosphere sign was identified as a critical marker for pneumothorax (Fig. 2). Portable CXR verified a rightdominant large pneumothorax with a small degree of left lung collapse; thus, a chest tube was inserted on the right side without complications (Fig. 3). After passive decompression using a chest tube, her hemodynamic parameters fully recovered, and the surgery continued laparoscopically with the chest tube inserted and close monitoring of the left-side lung field using lung ultrasound and respiratory monitoring. The surgeon explored both the diaphragm and surrounding structures to detect any defects or injuries, but there were no specific abnormal findings (Fig. 4). The surgery was completed uneventfully, and 
Table 1 Serial changes in hemodynamic parameters during laparoscopic donor hepatectomy

\begin{tabular}{|c|c|c|c|c|c|c|c|c|c|}
\hline & & Laparosc & ic surgery & & & & & & \\
\hline & & Beginnin & urgery & & $+30 \min$ & +45 & $+60 \min$ & $+240 \min$ & End of \\
\hline & $\begin{array}{l}\text { Anesthetic } \\
\text { induction }\end{array}$ & $\begin{array}{l}\text { Trocar } \\
\text { insertion }\end{array}$ & $\begin{array}{l}\mathrm{CO}_{2} \\
\text { insufflation }\end{array}$ & $\begin{array}{l}\text { Head-up } \\
\text { position }\end{array}$ & $\begin{array}{l}\text { Lung } \\
\text { ultrasound }^{\mathrm{a}}\end{array}$ & CXR & $\begin{array}{l}\text { Chest tube } \\
\text { insertion }\end{array}$ & $\begin{array}{l}\text { Hepatic artery } \\
\text { clamping }\end{array}$ & $\begin{array}{l}\text { Follow-up } \\
\text { CXR }\end{array}$ \\
\hline $\begin{array}{l}\text { SBP } \\
(\mathrm{mmHg})\end{array}$ & 111 & 91 & 104 & 101 & 82 & 104 & 147 & 106 & 123 \\
\hline $\begin{array}{l}\mathrm{DBP} \\
(\mathrm{mmHg})\end{array}$ & 76 & 49 & 63 & 65 & 41 & 68 & 98 & 67 & 59 \\
\hline $\begin{array}{l}\text { HR (beats/ } \\
\text { min) }\end{array}$ & 80 & 72 & 78 & 80 & 110 & 81 & 90 & 81 & 78 \\
\hline BIS & 40 & 42 & 45 & 50 & 46 & 45 & 45 & 44 & 44 \\
\hline BT $\left({ }^{\circ} \mathrm{C}\right)$ & 36.5 & 36.5 & 36.4 & 36.4 & 36.3 & 36.2 & 36.2 & 36.1 & 36 \\
\hline $\begin{array}{l}\text { APP } \\
\left(\mathrm{mmH}_{2} \mathrm{O}\right)\end{array}$ & 15 & 15 & 18 & 17 & 38 & 25 & 15 & 17 & 16 \\
\hline $\mathrm{TV}(\mathrm{mL})$ & 400 & 400 & 380 & 410 & 180 & 310 & 400 & 400 & 400 \\
\hline $\mathrm{SpO}_{2}(\%)$ & 99 & 100 & 98 & 100 & 88 & 92 & 100 & 100 & 100 \\
\hline $\begin{array}{l}\mathrm{ETCO}_{2} \\
(\mathrm{mmHg})\end{array}$ & 30 & 30 & 35 & 34 & 48 & 38 & 35 & 35 & 30 \\
\hline
\end{tabular}

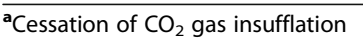

Abbreviation: CXR Chest X-ray, SBP Systolic blood pressure, DBP Diastolic blood pressure, $H R$ Heart rate, BIS Bispectral index, $B T$ Body temperature, $A P P$ Airway peak pressure, $T V$ Tidal volume, $\mathrm{SpO}_{2}$ Oxygen saturation, $\mathrm{ETCO}_{2}$ End tidal $\mathrm{CO}_{2}$

after manual deflation of the abdomen, an alveolar recruitment maneuver (i.e., manual inflation of 30 $\mathrm{cmH}_{2} \mathrm{O}$ for $30 \mathrm{~s}$ ) was performed several times. We confirmed the return of both equal breath sounds, and the donor was extubated and transported to the postanesthesia care unit.

The postoperative recovery course was uneventful, and follow-up CXR and CT images revealed complete resolution of the two-sided pneumothorax (Fig. 5). She was discharged on postoperative day 5 without any complications.

\section{Discussion}

The main lessons of this case are that anesthesiologists and surgeons should promptly and accurately diagnose and manage a pneumothorax that may threaten living donor safety, such as a tension pneumothorax. During laparoscopic liver donation surgery, point-of-care lung ultrasound was an accessible and reproducible diagnostic tool for the pneumothorax with the 'stratosphere sign' $[9,12]$. Early identification of the pneumothorax using point-of-care lung ultrasound led to timely management of the pneumothorax during surgery without fatal

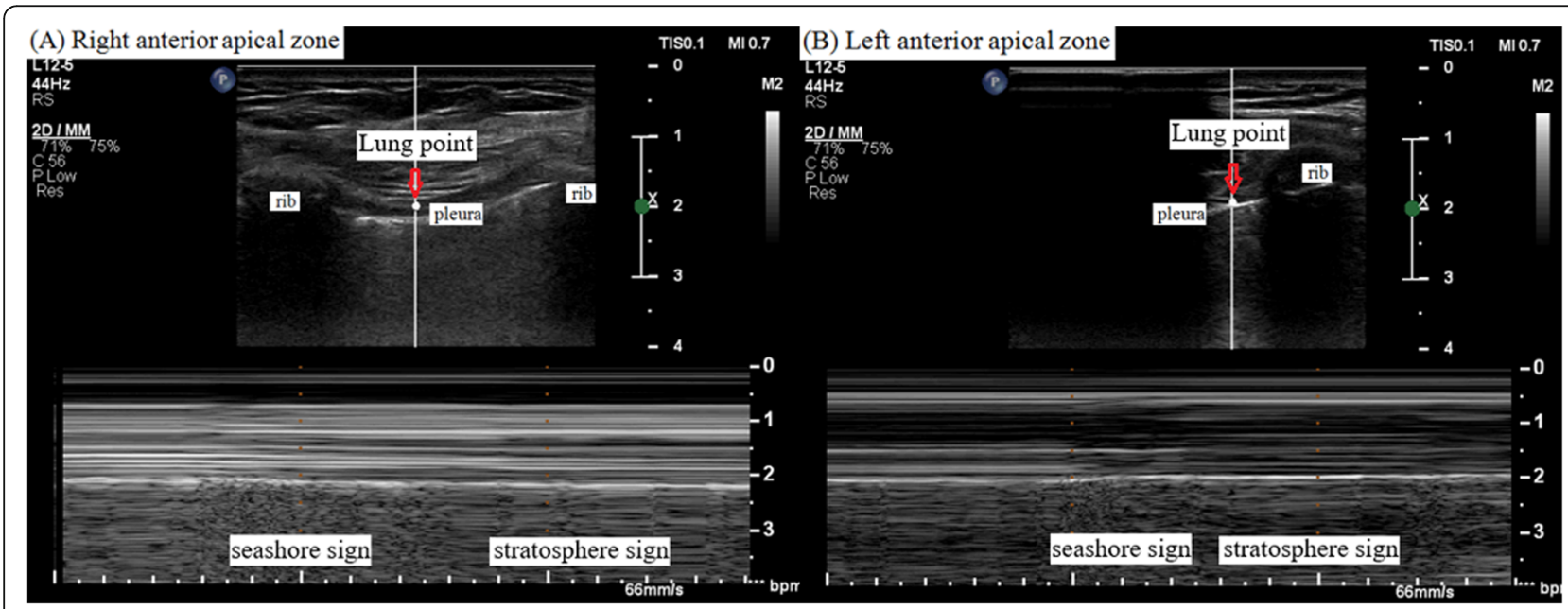

Fig. 1 Lung point on point-of-care lung ultrasound. a Right anterior apical zone. b Left anterior apical zone. Arrows indicate the lung point where the normal lung pattern (i.e., seashore sign) replaces the pneumothorax pattern (i.e., stratosphere sign) with inspiration 


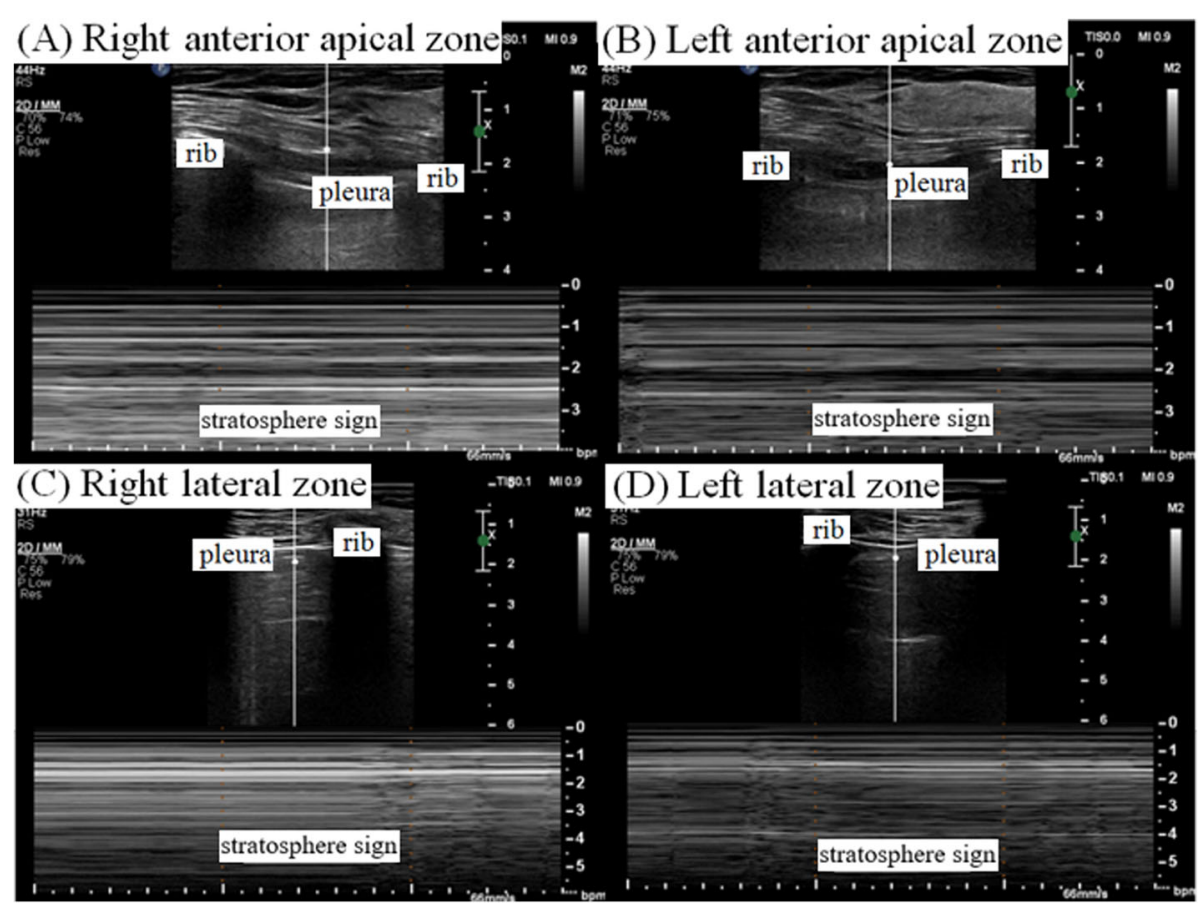

Fig. 2 Stratosphere sign on point-of-care lung ultrasound. a Right anterior apical zone. b Left anterior apical zone. c Right lateral zone. $\mathbf{d}$ Left lateral zone

complications, and our donor was discharged without sequela.

Although pneumothorax, as a complication of laparoscopic surgery, is rare, several cases have been reported [13-16]. A study by Pizzo et al. [4] suggested that in 1765 patients undergoing laparoscopic renal surgery, 10 patients $(0.6 \%)$ intraoperatively experienced pleural injury that subsequently led to pneumothorax; they involved inadvertent trocar placement (2 patients) during splenic ( 2 patients), liver (2 patients), or ascending colon (1 patient) mobilization, and dissection of the upper renal pole ( 2 patients) and of a large renal cyst off of the diaphragm (1 patient). A study by Murdock et al. [16] suggested that in 968 patients undergoing laparoscopy-

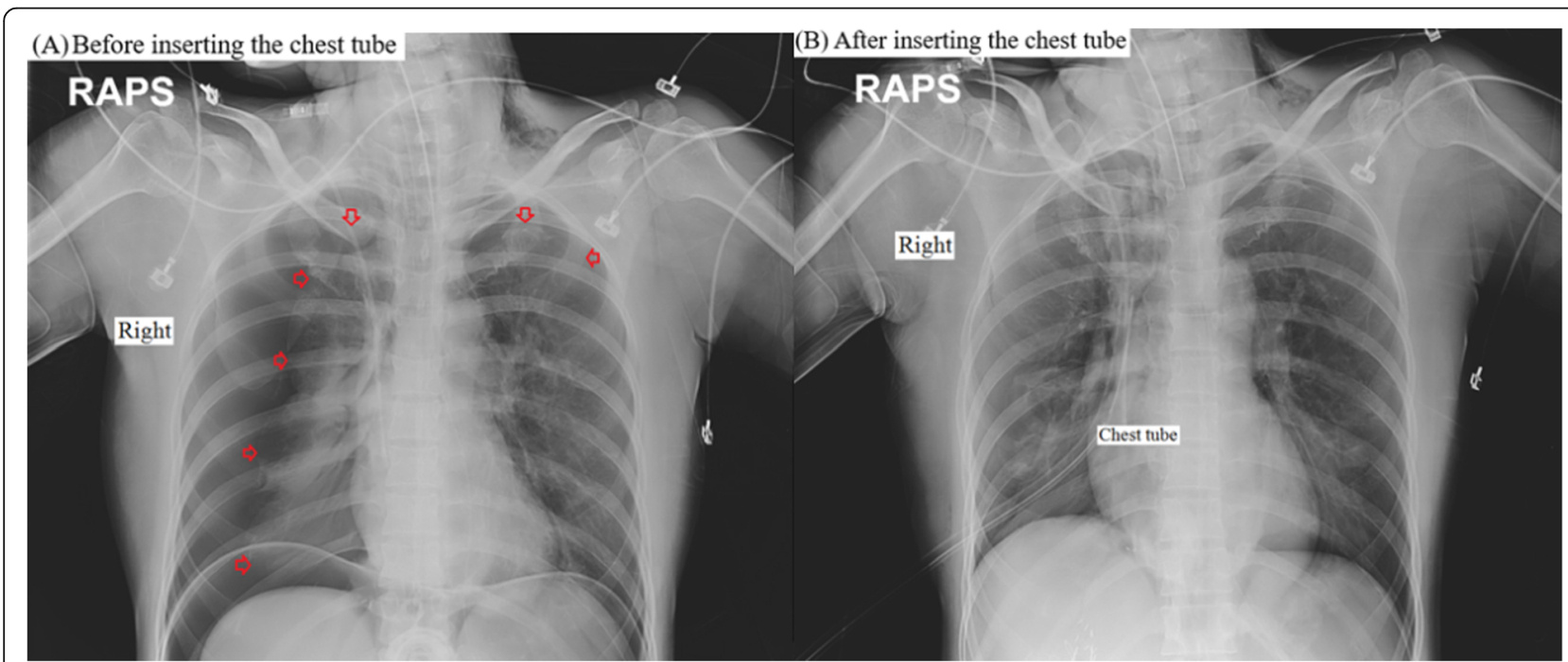

Fig. 3 Chest radiography. a Before inserting the chest tube. $\mathbf{b}$ After inserting the chest tube. Arrows indicate the visceral pleural line with the absence of vascular marking beyond the pleural line 


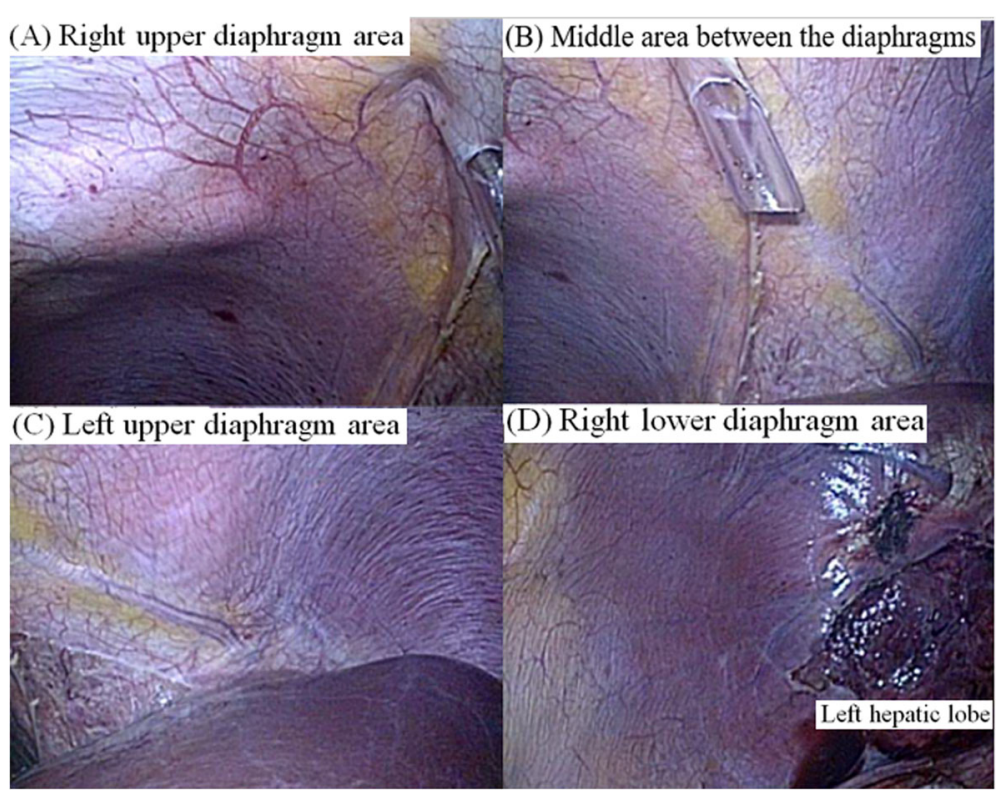

Fig. 4 Endoscopic diaphragmatic view. a Right upper diaphragm area. b Middle area between the diaphragms. c Left upper diaphragm area. d Right lower diaphragm area

based surgery, the incidence of pneumothorax/pneumomediastinum was $1.9 \%$ and was markedly related to prolonged surgical manipulation and a large amount or pressure of $\mathrm{CO}_{2}$ gas insufflation.

An intraoperative pneumothorax may largely originate from iatrogenic procedures and/or congenital defects. The iatrogenic causes include barotrauma and rupture of emphysematous bullae or a bleb due to mechanical ventilation, direct injury to the diaphragm during surgical dissection, central line malpractice, or errant trocar implementation [17-19]. A $\mathrm{CO}_{2}$ pneumothorax can be caused by congenital defects in the diaphragm or other defects/fistulas around sites where the aorta, vena cava, and esophagus traverse the diaphragm [20-22]. In addition, various intraoperative factors, including a higher $\mathrm{ETCO}_{2}$ level (i.e., $\geq 50 \mathrm{mmHg}$ ), prolonged operation duration (i.e., $\geq 200 \mathrm{~min}$ ), and rapid and higher $\mathrm{CO}_{2}$ insufflation pressure, may account for a pneumothorax $[17,23] . \mathrm{A} \mathrm{CO}_{2}$ pneumothorax is more likely to occur on the right side during hepatic side surgery, such as a laparoscopic cholecystectomy, because of surgical exposure of the omentum, which naturally covers a diaphragmatic defect or weak point $[24,25]$. The surgical heads-up position with $\mathrm{CO}_{2}$ gas insufflation may increase the risk for pneumothorax because the position may push the liver and omentum downward and eventually result in exposure of a diaphragmatic defect in the pressurized abdominal cavity. In our case, it was difficult

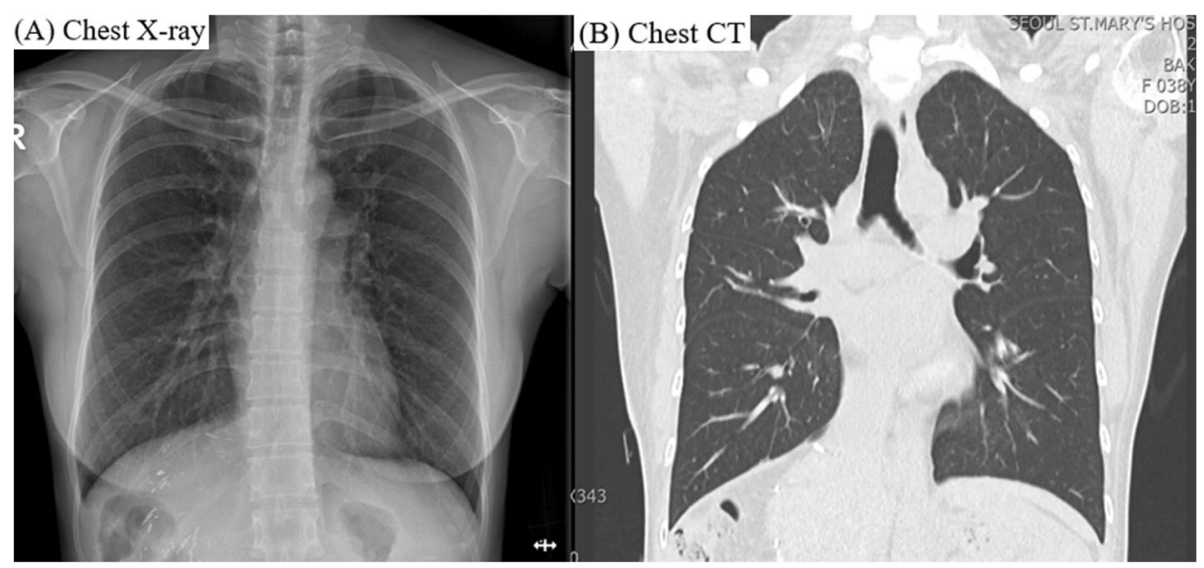

Fig. 5 a Chest radiography and $\mathbf{b}$ computed tomography $(C T)$ at hospital discharge 
to diagnose the pneumothorax intraoperatively and to decide whether it was suitable to perform invasive therapies, such as implemented thoracocentesis or placing a chest tube because the surgical and anesthetic practices were uneventful; $\mathrm{CO}_{2}$ gas insufflation pressure was acceptable, and our living donor was young and healthy. However, a diaphragmatic defect cannot be excluded and suprahepatic surgical exploration may injure the diaphragm by accident. $\mathrm{CO}_{2}$ gas can also dissect into the pleural space along the vena cava. Additionally, because pathologic findings of the chest, including bullae or a macro-shunt, were not found in preoperative chest CT images, a micro-channel of iatrogenic or congenital origin between the abdominal and chest cavities may have been largely responsible for insufflation of the $\mathrm{CO}_{2}$ gas into the right lung field and subsequently the occurrence of pneumothorax. Although breath sounds and chest wall motion of both lung fields seemed to be normal during manual Ambu-bagging, the respiratory signs of pneumothorax, such as increases in $\mathrm{ETCO}_{2}$ and airway pressure and a decrease in $\mathrm{SpO}_{2}$, gradually developed during the $\mathrm{CO}_{2}$ pneumoperitoneum, and severity worsened as the surgery progressed. We performed a sonographic assessment and detected a $\mathrm{CO}_{2}$ pneumothorax without pulmonary origin that stopped $\mathrm{CO}_{2}$ gas insufflation and prevented hemodynamic aggravation.

The absence of lung sliding, where air separates the visceral and parietal pleurae, is demonstrated via $\mathrm{M}$ mode ultrasonography as a linear pattern from superficial tissue to the pleural line and a similar pattern from the pleural line to deep tissue known as the 'stratosphere (barcode) sign or lung sliding sign'. This sonographic finding highly suggests a pneumothorax (i.e., 95\% sensitivity; $100 \%$ negative predictive value; and $87 \%$ positive predictive value) [26, 27]. The point where the normal lung pattern (i.e., seashore sign) replaces the pneumothorax pattern (i.e., stratosphere sign) with inspiration, is known as the 'lung point,' which significantly suggests occult or partial pneumothorax [28]. In addition, lung ultrasound is more efficient and better for diagnosing a pneumothorax in emergency cases than bedside CXR [28]. The time spent diagnosing a pneumothorax can be reduced using lung ultrasound compared to CXR [29]. Although lung CT has been established as the gold standard for diagnosing pathological lung conditions, including a pneumothorax, patients undergoing surgery in an operating room have limited use of CT [30]. In our case, lung ultrasound provided accurate evidence for the pneumothorax, and appropriately guided intraoperative donor care, including avoiding a pneumoperitoneum and performing the chest tube drainage. Based on practical guidelines recommending that the ultrasound examination should systematically cover both lung fields which are divided into six regions, such as upper and lower parts of the anterior, lateral and posterior chest wall using anterior- and posterior-axillary lines as anatomical landmarks, in the supine position setting [9, 12, 30], we examined both lung fields and successfully verified the barcode sign during surgery. Considering the relationship between the position of a surgical patient and air collection sites, the sonographic probe should be properly located in the operating room. In addition, close communication and collaboration between surgeons and anesthesiologists over surgical, hemodynamic, and sonographic findings are essential to minimize the risk for a fatal prognosis.

This living donor case suggests that a pneumothorax can unexpectedly occur during laparoscopic hepatectomy due to the escape of intraperitoneal $\mathrm{CO}_{2}$ gas into the pleural cavity through a potential micro-channel of iatrogenic or congenital origin between the abdomen and chest. Although $\mathrm{CO}_{2}$ pneumothorax is well tolerated and rapidly reversed after the release of the pneumoperitoneum, unlike a pneumothorax secondary to lung trauma [13, 31, 32], missing the chance to identify a pneumothorax early significantly decreases safety for living donors. Point-of-care lung ultrasound is considered a better imaging technique than CXR and an alternative imaging technique to $\mathrm{CT}$ during laparoscopic donor hepatectomy, and it will help attending physicians reach the final diagnosis of intraoperative pneumothorax more rapidly and plan treatments more effectively.

\section{Supplementary information}

Supplementary information accompanies this paper at https://doi.org/10. 1186/s12893-020-00868-8.

\section{Additional file 1.}

\section{Abbreviations}

LT: Liver transplantatio; CXR: Chest radiography; CT: Computed tomography; SBP: Systolic blood pressure; DBP: Diastolic blood pressure; HR: Heart rate; $\mathrm{SpO}_{2}$ : Saturation of peripheral oxygen; $\mathrm{ETCO}_{2}$ : End tidal $\mathrm{CO}_{2}$

\section{Acknowledgments}

All authors thank Eunju Choi, Hyeji An and Hyunsook Yoo (Anesthesia Nursing Unit, Seoul St. Mary's Hospital, The Catholic University of Korea, Seoul, Republic of Korea) for their support and dedication.

\section{Authors' contributions}

M.S.C. was responsible for collecting the data of the patient, follow up, and preparation of the manuscript. M.S.C., J.K., K.R., M.K., S.P., H.J.C., J.P., J.W.S., H.M.L., Y.S.K., Y.E.M. and S.H.H. participated in the anesthesia and care of the living donor and were responsible for revision of the manuscript. All authors read and approved the final manuscript.

Funding

No funding was used for this work.

Availability of data and materials

All data and materials described in the manuscript will be freely available for non-commercial purposes. 


\section{Ethics approval and consent to participate}

The Institutional Review Board of Seoul St. Mary's Hospital Ethics Committee approved to the present case report.

\section{Consent for publication}

Written informed consent was obtained from the patient for publication of this case report.

\section{Competing interests}

The authors have no conflicts of interest to declare.

\section{Author details}

'Department of Anesthesiology and Pain Medicine, Seoul St. Mary's Hospital, College of Medicine, The Catholic University of Korea, 222, Banpo-daero, Seocho-gu, Seoul 06591, Republic of Korea. ${ }^{2}$ Department of Anesthesiology and Pain Medicin, Yeouido St. Mary's Hospital, College of Medicine, The Catholic University of Korea, Seoul, Republic of Korea. ${ }^{3}$ Department of Anesthesiology and Pain Medicine, Eunpyeong St. Mary's Hospital, College of Medicine, The Catholic University of Korea, Seoul, Republic of Korea. ${ }^{4}$ Department of Anesthesiology and Pain Medicine, Bucheon St. Mary's Hospital, College of Medicine, The Catholic University of Korea, Seoul, Republic of Korea. ${ }^{5}$ Department of Surgery, Seoul St. Mary's Hospital, College of Medicine, The Catholic University of Korea, Seoul, Republic of Korea.

Received: 27 March 2020 Accepted: 8 September 2020

Published online: 16 September 2020

\section{References}

1. Hamilton BD, Gatti JM, Cartwright PC, Snow BW. Comparison of laparoscopic versus open nephrectomy in the pediatric population. J Urol. 2000;163(3):937-9.

2. Kwon CHD, Choi GS, Joh JW. Laparoscopic right hepatectomy for living donor. Curr Opin Organ Transplant. 2019;24(2):167-74.

3. Mamić I, Danolić D, Puljiz M, Kasum M, Alvir I, Kostić L, Milas I, Šoštar A, Pedišić I, Bečejac T. Pneumothorax and Pneumomediastinum as a rare complication of laparoscopic surgery. Acta Clin Croat. 2016;55(3):501-4.

4. Del Pizzo JJ, Jacobs SC, Bishoff JT, Kavoussi LR, Jarrett TW. Pleural injury during laparoscopic renal surgery: early recognition and management. J Urol. 2003;169(1):41-4.

5. Bekemeyer WB, Crapo RO, Calhoon S, Cannon CY, Clayton PD. Efficacy of chest radiography in a respiratory intensive care unit. A prospective study. Chest. 1985;88(5):691-6.

6. Greenbaum DM, Marschall KE. The value of routine daily chest x-rays in intubated patients in the medical intensive care unit. Crit Care Med. 1982; 10(1):29-30.

7. Beckmann U, Gillies DM, Berenholtz SM, Wu AW, Pronovost P. Incidents relating to the intra-hospital transfer of critically ill patients. An analysis of the reports submitted to the Australian incident monitoring study in intensive care. Intensive Care Med. 2004;30(8):1579-85.

8. Mayo JR, Aldrich J, Muller NL. Radiation exposure at chest CT: a statement of the Fleischner society. Radiology. 2003;228(1):15-21.

9. Shrestha GS, Weeratunga D, Baker K. Point-of-care lung ultrasound in critically ill patients. Rev Recent Clin Trials. 2018;13(1):15-26.

10. Miller CM, Durand F, Heimbach JK, Kim-Schluger L, Lee SG, Lerut J, Lo CM, Quintini C, Pomfret EA. The international liver transplant society guideline on living liver donation. Transplantation. 2016;100(6):1238-43.

11. Kim YH, Park UJ, Chung HS, Hong SH, Park CS, Choi JH, Choi HJ, Jung JY, Chae MS. Recovery of the psoas muscle index in living donors after a right lobe hepatectomy for liver transplantation: a single-center experience. Transplant Proc. 2019;51(6):1853-60.

12. Lichtenstein DA. BLUE-protocol and FALLS-protocol: two applications of lung ultrasound in the critically ill. Chest. 2015;147(6):1659-70.

13. Wu Q, Zhang H. Carbon dioxide pneumothorax following retroperitoneal laparoscopic partial nephrectomy: a case report and literature review. BMC Anesthesiol. 2018;18(1):202.

14. Matsushita Y, Miyake H, Motoyama D, Sugiyama T, Nagata M, Otsuka A, Furuse H, Ozono S. Contralateral pneumothorax during retroperitoneal laparoscopic donor nephrectomy: a case report. Asian J Endosc Surg. 2017; 10(2):202-4.
15. Shenoy S, Cassim R. Pneumothorax and pneumomediastinum after laparoscopic total extraperitoneal groin hernia repair: benign or cause for concern. Am Surg. 2012;78(1):146-7.

16. Ozasa H, Uchida H, Moto-Oka A, Toyota K, Saito Y. Intraoperative pneumothrax during retroperitoneal laparoscopic surgery. J Anesth. 2004; 18(4):318-9.

17. Murdock CM, Wolff AJ, Van Geem T. Risk factors for hypercarbia, subcutaneous emphysema, pneumothorax, and pneumomediastinum during laparoscopy. Obstet Gynecol. 2000;95(5):704-9.

18. Wahba RW, Tessler MJ, Kleiman SJ. Acute ventilatory complications during laparoscopic upper abdominal surgery. Can J Anaesth. 1996;43(1):77-83.

19. Reeson M, Forster A, van Walraven C. Incidence and trends of central line associated pneumothorax using radiograph report text search versus administrative database codes. BMJ Qual Saf. 2018;27(12):982-8.

20. Park HJ, Kim DK, Yang MK, Seo JE, Kwon JH. Carbon dioxide pneumothorax occurring during laparoscopy-assisted gastrectomy due to a congenital diaphragmatic defect: a case report. Korean J Anesthesiol. 2016;69(1):88-92.

21. Soro J, Blanco M, Garcia-Fontan E. Pneumothorax and congenital diaphragmatic hernia: an unusual combination. Arch Bronconeumol. 2015; 51(12):655.

22. Karaci M, Toroslu E, Tatli D, Unlu M, Piskin IE. Late presenting congenital diaphragmatic hernia as tension gastrothorax. Indian J Pediatr. 2015;82(5): 483-4.

23. Sucandy I, Kolff JW. Pneumothorax after laparoscopic extraperitoneal inguinal hernia repair: a potential complication that every general surgeon should know. Am Surg. 2012;78(2):64-5

24. Prystowsky JB, Jericho BG, Epstein HM. Spontaneous bilateral pneumothorax--complication of laparoscopic cholecystectomy. Surgery. 1993;114(5):988-92.

25. Gabbott DA, Dunkley AB, Roberts FL. Carbon dioxide pneumothorax occurring during laparoscopic cholecystectomy. Anaesthesia. 1992;47(7): 587-8.

26. Lichtenstein D. Lung ultrasound in the critically ill. Curr Opin Crit Care. 2014; 20(3):315-22.

27. Lichtenstein DA, Menu Y. A bedside ultrasound sign ruling out pneumothorax in the critically ill. Lung sliding. Chest. 1995;108(5):1345-8.

28. Lichtenstein DA, Mezière G, Lascols N, Biderman P, Courret JP, Gepner A, Goldstein I, Tenoudji-Cohen M. Ultrasound diagnosis of occult pneumothorax. Crit Care Med. 2005;33(6):1231-8.

29. Zhang M, Liu ZH, Yang JX, Gan JX, Xu SW, You XD, Jiang GY. Rapid detection of pneumothorax by ultrasonography in patients with multiple trauma. Crit Care (London, England). 2006;10(4):R112.

30. Bouhemad B, Zhang M, Lu Q, Rouby JJ. Clinical review: Bedside lung ultrasound in critical care practice. Crit Care (London, England). 2007;11(1): 205.

31. Phillips S, Falk GL. Surgical tension pneumothorax during laparoscopic repair of massive hiatus hernia: a different situation requiring different management. Anaesth Intensive Care. 2011;39(6):1120-3.

32. Karayiannakis AJ, Anagnostoulis S, Michailidis K, Vogiatzaki T, Polychronidis A, Simopoulos C. Spontaneous resolution of massive right-sided pneumothorax occurring during laparoscopic cholecystectomy. Surg Laparosc Endosc Percutan Tech. 2005;15(2):100-3.

\section{Publisher's Note}

Springer Nature remains neutral with regard to jurisdictional claims in published maps and institutional affiliations.

Ready to submit your research? Choose BMC and benefit from:

- fast, convenient online submission

- thorough peer review by experienced researchers in your field

- rapid publication on acceptance

- support for research data, including large and complex data types

- gold Open Access which fosters wider collaboration and increased citations

- maximum visibility for your research: over $100 \mathrm{M}$ website views per year

At BMC, research is always in progress.

Learn more biomedcentral.com/submissions 